\title{
CONTENTS TO VOL. 5, NO. 1
}

A Bibliographical Clavis to the Corpus of Works attributed to Isaac of Antioch 3

Edward G. Mathews, Jr.

"Exchanging Reed for Reed": Mapping Contemporary Heretics onto Biblical Jews in Ephrem's Hymns on Faith ........15 Christine C. Shepardson......

The Image of the Infant Jesus in Ephrem the Syrian 35 Paul S. Russell......

Some Basic Annotation to The Hidden Pearl: The Syrian Orthodox Church And Its Ancient Aramaic Heritage, I-III (Rome, 2001)

Sebastian P. Brock.

PUBLICATIONS AND BOOK REVIEWS 